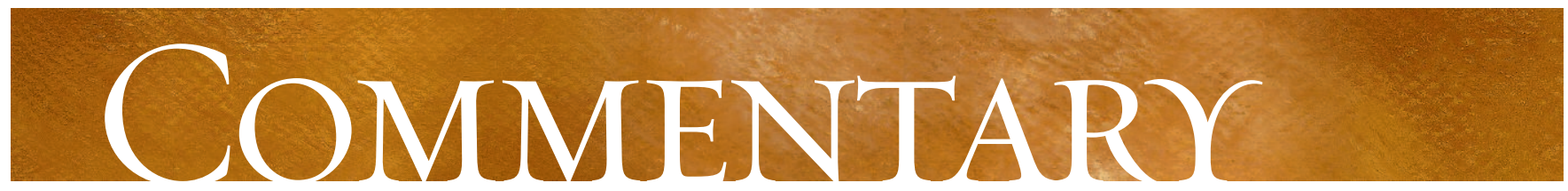

\title{
Homelessness and harm reduction
}

\section{Stephen W. Hwang}

$\infty$

See related article page 45

$\mathrm{E}$ very night, about 800 ooo Americans and tens of thousands of Canadians sleep on the street or in homeless shelters. ${ }^{1,2}$ Countless more stay temporarily with friends or relatives because they have no home of their own. ${ }^{3}$ Those who experience homelessness represent a remarkably diverse group: of the 32000 people who used homeless shelters in Toronto in 2002, $15 \%$ were families with children, $22 \%$ were street youths between the ages of 15 and 24 years, I $8 \%$ were single women and $48 \%$ were single men. ${ }^{4}$

Most people use homeless shelters for a period of weeks to months before finding housing in the community, but some $10 \%-20 \%$ of shelter residents are chronically homeless. ${ }^{5,6}$ These people, for whom the shelters are a kind of semipermanent home, suffer from high rates of alcohol and drug addiction. ${ }^{5}$

Fortunately, substance abuse in homeless people is amenable to intervention. A recent systematic review has shown that a variety of coordinated treatment programs designed to meet the needs of homeless people are effective in reducing alcohol and drug use. ${ }^{7}$ However, these programs are intended for those who wish to refrain from substance use. Helping chronically homeless people with severe alcoholism who do not want to stop drinking remains difficult.

In an important study published in this issue of $C M A J$ (page 45), Podymow and colleagues ${ }^{8}$ describe an innovative shelter-based program for this subgroup of the homeless population. Instead of making abstinence from alcohol an objective, their "managed alcohol" intervention sought to minimize personal harm and adverse societal effects. ${ }^{9}$ The program provided close supervision, assistance with activities of daily living, on-site health care and, most notably, a maximum of one standard drink ( $13.6 \mathrm{~g}$ of alcohol) hourly on demand during the waking hours.

The investigators examined outcomes among 17 participants using a before-and-after design. The number of emergency department visits dropped significantly, from an average of 0.79 visits per month before program entry to $0.5 \mathrm{I}$ during the program. Encounters with police also decreased significantly, and there was a nonsignificant trend toward fewer days in hospital. Data derived from the retrospective self-reports and program records of Io participants showed a considerable decrease in estimated alcohol intake after enrolment.
This study has several limitations that must be borne in mind. The sample was very small, and the lack of a control or comparison group precludes any firm conclusions about the effectiveness of the program. In addition, the accuracy of participants' estimated alcohol use is uncertain, and data on changes in health status are lacking. Nonetheless, this novel study is a tantalizing demonstration of the feasibility and potential value of a pioneering harm-reduction program for this difficult-to-serve population.

\section{... Harm reduction stra- tegies are intended to complement, rather than replace, more traditional means of treatment.}

In recent years, harm-reduction strategies have perhaps been most prominent in initiatives for injection drug users. Interventions such as needle-exchange programs $\mathrm{s}^{10}$ and supervised injection sites ${ }^{11,12}$ have been the subject of intense controversy as well as substantial research. Harm-reduction approaches to alcohol abuse will likely face similar challenges. In particular, some clinicians and members of the public may have reservations about providing alcohol to people with alcoholism. These concerns may be partially allayed by an understanding that harm-reduction strategies are intended to complement, rather than replace, more traditional means of treatment. In addition, pragmatic efforts to mitigate the adverse health consequences of a harmful behaviour need not be construed as a sanctioning of the behaviour itself.

The critical scientific question is whether a managed alcohol program for homeless people results in better outcomes than traditional abstinence-based programs. If so, which individuals are most likely to benefit from such an approach? Until we have data from controlled trials, these issues will re- 
main unresolved. In the meantime, the staff and health care providers at managed alcohol programs such as the one described in this study must be applauded for their commitment to caring for some of the most marginalized members of our society.

Stephen Hwang is with the Centre for Research on Inner City Health, St. Michael's Hospital, and the Division of General Internal Medicine, University of Toronto, Toronto, Ont.

Competing interests: None declared.

\section{REFERENCES}

I. Burt M, Aron LY, Lee E, et al. Helping America's homeless: Emergency shelter or affordable housing? Washington: Urban Institute Press; 200I.

2. Hwang SW. Homelessness and health. $C M A J$ 200I;164(2):229-33.

3. Bolland JM, McCallum DM. Touched by homelessness: an examination of hospitality for the down and out. Am J Public Health 2002;92:116-8.

4. City of Toronto. The Toronto report card on housing and homelessness 2003. Available: www.toronto.ca/homelessness (accessed 2005 Nov 22).
5. Kuhn R, Culhane DP. Applying cluster analysis to test a typology of homelessness by pattern of shelter utilization: results from the analysis of administrative data. Am J Community Psychol I998;26:207-32.

6. Caton CL, Dominguez B, Schanzer B, et al. Risk factors for long-term homelessness: findings from a longitudinal study of first-time homeless single adults. Am J Public Health 2005;95:1753-9.

7. Hwang SW, Tolomiczenko G, Kouyoumdjian FG, et al. Interventions to improve the health of the homeless: a systematic review. Am J Prev Med 2005;29:3II-9.

8. Podymow T, Turnbull J, Coyle D, et al. Shelter-based managed alcohol administration to chronically homeless people addicted to alcohol. $C M A J$ 2006;174(I):45-9.

9. Hass J. Harm-reduction initiative provides alcohol to Ottawa's street alcoholics. CMAJ 200I; 65 (7):937.

Io. Vlahov D, Des Jarlais DC, Goosby E, et al. Needle exchange programs for the prevention of human immunodeficiency virus infection: epidemiology and policy. Am JEpidemiol 200I;154(12 Suppl):S70-7.

II. Wood E, Kerr T, Lloyd-Smith E, et al. Methodology for evaluating Insite: Canada's first medically supervised safer injection facility for injection drug users. Harm Reduct J 2004;1:9.

I2. Wood E, Kerr T, Small W, et al. Changes in public order after the opening of a medically supervised safer injecting facility for illicit injection drug users. CMAJ 2004;I7I(7):73I-4.

Correspondence to: Dr. Stephen W. Hwang, Centre for Research on Inner City Health, St. Michael's Hospital, 30 Bond St., Toronto ON M5B IW8; fax 4I6 864-5485; hwangs@smh.toronto.on.ca

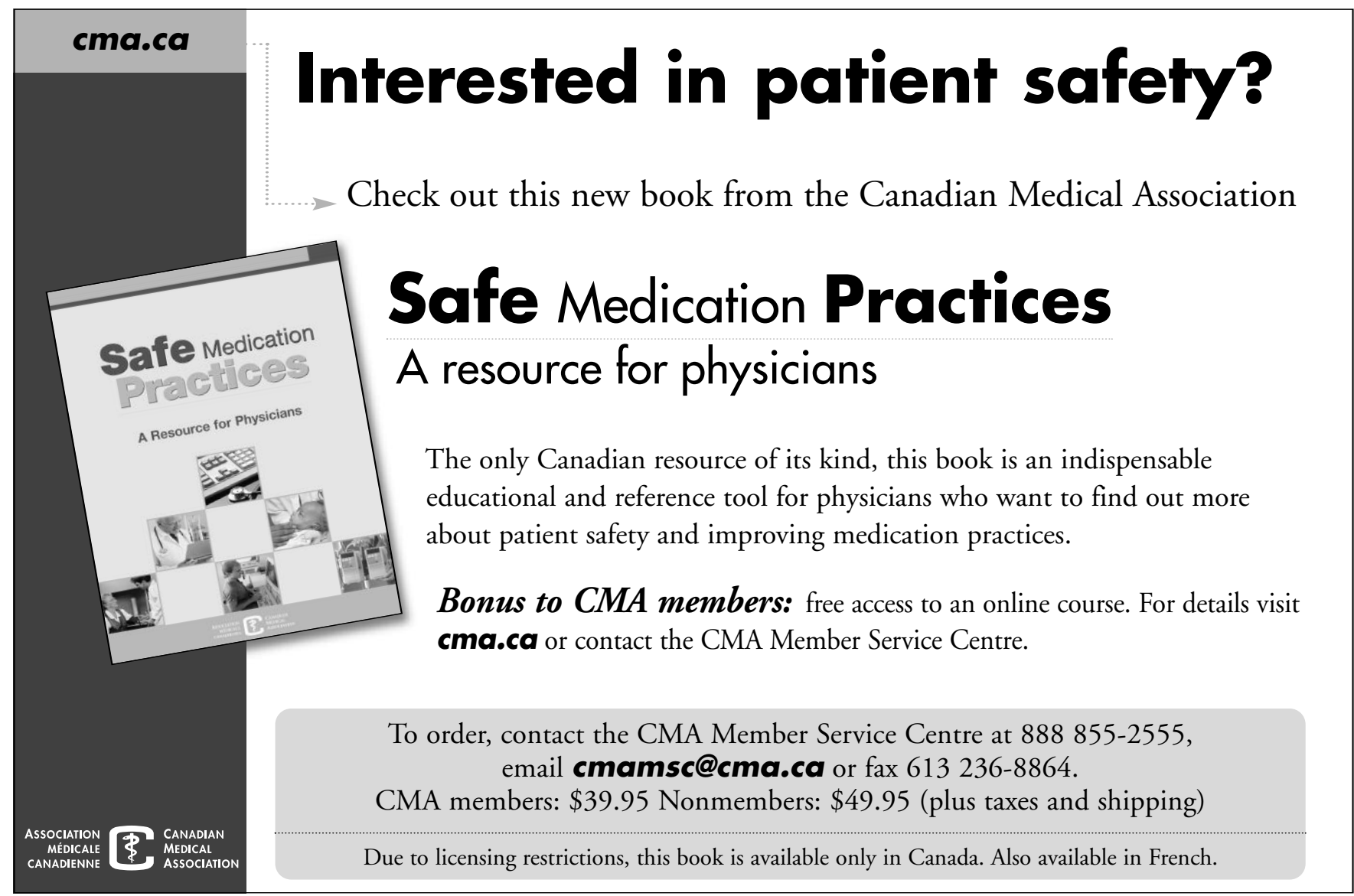

